\title{
Amyotrophic lateral sclerosis
}

INSERM

\section{Source}

INSERM. (1999). Orphanet: an online rare disease and orphan drug data base.

Amyotrophic lateral sclerosis. ORPHA:803

Amyotrophic lateral sclerosis (ALS) is a neurodegenerative disease characterized by progressive muscular paralysis reflecting degeneration of motor neurons in the primary motor cortex, corticospinal tracts, brainstem and spinal cord. 